\title{
Faktor-faktor motivasi yang dipertimbangkan masyarakat dalam pemilihan perbankan syariah (Studi pada Bank BTN Syariah)
}

\author{
${ }^{1}$ R. Yudhistira Adi Seputra, ${ }^{2 *}$ Bhenu Artha \\ ${ }^{1}$ Universitas Bojonegoro, Jawa Timur, ${ }^{2}$ Universitas Widya Mataram, Yogyakarta \\ *e-mail korespondensi: bhenoz27@gmail.com
}

\begin{tabular}{l|l}
\hline \hline \multicolumn{1}{c}{ Article Info } & \multicolumn{1}{c}{ Abstract } \\
\hline \hline $\begin{array}{l}\text { Keywords: internal } \\
\text { motivations, } \\
\text { external } \\
\text { motivations, } \\
\text { customers }\end{array}$ & $\begin{array}{l}\text { The purpose of this study was to determine the internal and external motivations } \\
\text { considered by customers in saving funds at BTN Syariah Yogyakarta. This research } \\
\text { was conducted on 110 respondents. The results showed that internal and external } \\
\text { motivational factors were considered by customers in saving funds at BTN Syariah } \\
\text { Yogyakarta. Further results show that there is no difference in the customer's } \\
\text { internal and external motivations seen from the level of education and work. }\end{array}$ \\
\hline \hline \multicolumn{1}{c|}{$\begin{array}{l}\text { Info Artikel } \\
\text { Kata Kunci: } \\
\text { motivasi internal, } \\
\text { pelangasi eksternal, }\end{array}$} & $\begin{array}{l}\text { Tujuan dari penelitian ini adalah untuk mengetahui motivasi internal dan eksternal } \\
\text { yang dipertimbangkan nasabah dalam menyimpan dana di BTN Syariah Yogyakarta. } \\
\text { Penelitian ini dilakukan pada 110 responden. Hasil penelitian menunjukkan bahwa } \\
\text { faktor motivasi internal dan eksternal menjadi pertimbangan nasabah dalam } \\
\text { menabung di BTN Syariah Yogyakarta. Hasil lebih lanjut menunjukkan bahwa tidak } \\
\text { ada perbedaan motivasi internal dan eksternal pelanggan dilihat dari tingkat } \\
\text { pendidikan dan pekerjaan. }\end{array}$
\end{tabular}

\section{PENDAHULUAN}

Industri perbankan syariah di Indonesia semakin banyak jumlahnya, sampai saat ini jumlahnya mencapai 14 Bank Umum Syariah (BUS) dan 20 Unit Usaha Syariah (UUS) serta 163 Bank Pembiayaan Rakyat Syariah (BPRS). Salah satu BUS adalah Bank BTN Syariah. Sebagai salah satu perusahaan yang bergerak di sektor perbankan syariah, BTN Syariah banyak diminati masyarakat, terbukti dengan banyaknya masyarakat yang menjadi nasabahnya, baik nasabah yang menggunakan produk penghimpunan dana (funding) maupun produk penyaluran dana (financing). Sistem Syariah juga menjadi pilihan bagi para pengusaha untuk pembiayaan usaha mereka (Fathonih et al., 2019).

Sebagai salah satu bank syariah di Indonesia, khususnya di Yogyakarta, BTN Syariah memerlukan pemahaman terhadap perilaku konsumen, dalam hal ini nasabah, untuk memuaskan kebutuhan dan keinginan konsumen melalui proses pertukaran. Dengan mempelajari teori perilaku konsumen dan juga teori motivasi, maka diharapkan akan didapatkan dan diungkapkan konsep-konsep motivasi yang melandasi nasabah BTN Syariah 


\section{Entrepreneurship Bisnis Manajemen Akuntansi (E-BISMA), 2(2), 80-84 \\ R. Yudhistira Adi Seputra, Bhenu Artha}

Yogyakarta menentukan pilihan mereka. Analisis ini didasarkan pada motivasi konsumen dan diberikan solusi yang terbaik sehingga BTN Syariah Yogyakarta akan mampu memahami nasabahnya, dan dapat dijadikan pertimbangan dalam mengembangkan pemasaran di masa mendatang.

\section{KAJIAN TEORI DAN HIPOTESIS}

Motivasi bukanlah suatu kesatuan fenomena, orang tidak hanya memiliki jumlah tingkat motivasi yang berbeda (berapa banyak motivasi), tetapi juga jenis motivasi orientasi motivasi tersebut (jenis motivasi apa) (Hrbackova \& Suchankova, 2016). Orientasi motivasi menyangkut sikap dan tujuan yang mendasari yang menimbulkan tindakan - yaitu, menyangkut mengapa tindakan tersebut dilakukan dan motivasi ini bervariasi dari motivasi yang sangat sedikit untuk bertindak hingga motivasi yang sangat besar (Hrbackova \& Suchankova, 2016).

Motivasi intrinsik, kesukaan, manajemen waktu, dan prestasi terkait erat; mereka bisa saling mempengaruhi dari waktu ke waktu (Xu et al., 2020). Menurut teori selfdetermination (Ryan \& Deci, 2000), ada dua jenis motivasi umum untuk terlibat dalam suatu kegiatan: motivasi ekstrinsik dan motivasi intrinsik. Motivasi intrinsik didefinisikan sebagai terlibat dalam suatu kegiatan untuk sifat dan kepuasan yang melekat (misalnya, untuk mengeksplorasi, belajar, dan untuk memperluas kapasitas seseorang), sedangkan motivasi ekstrinsik mengacu pada keterlibatan suatu kegiatan untuk kualitas instrumental atau konsekuensi yang dapat dipisahkan, misalnya, untuk mencari persetujuan, untuk menerima penghargaan, atau untuk menghindari rasa bersalah (Ryan \& Deci, 2000).

Motivasi memiliki peran dalam merumuskan perilaku dan tindakan seseorang (Zhang et al., 2008). Ketika seseorang tidak termotivasi, orang tersebut tidak akan merasakan dorongan atau inspirasi untuk bertindak atas sesuatu (Bastari et al., 2020). Motivasi intrinsik juga telah diperdebatkan sebagai penentu utama partisipasi dalam aktivitas apa pun (Hsu, 2017). Motivasi intrinsik dapat diekspresikan sebagai persepsi melakukan suatu aktivitas oleh pengguna untuk kesenangan dan kepuasan, dan perilaku yang termotivasi secara intrinsik akan sukarela dan ditentukan sendiri dan secara optimal melibatkan individu dalam aktivitas tertentu yang mereka anggap menarik, baru, dan menantang (Chaurasia et al., 2019).

Ekonomi Islam, yang mempromosikan reformasi berdasarkan ajaran Islam, memandang pasar sebagai alat efisiensi ekonomi dan dengan cara pandang yang sama, maka kebebasan ekonomi yang tidak terkekang menghasilkan ketidakadilan (Çokgezen \& Kuran, 2015). Agar pasar menghasilkan hasil yang adil, para pemain harus mengikuti prinsipprinsip perilaku Islami dan hasil ekonomi yang unggul secara etis pada akhirnya lebih memuaskan akan muncul ketika transaksi keuangan memperhatikan apa yang dilarang dalam ajaran Islam (Çokgezen \& Kuran, 2015).

Difusi informasi terutama merupakan model penyebaran rumor yang dikembangkan berdasarkan epidemic model (Sun et al., 2020). Diasumsikan bahwa hubungan antara orangorang tidak diketahui, dan hubungan ini merupakan jaringan yang tidak terlihat, oleh karena itu, karena alasan kepercayaan, mereka lebih suka menerima rekomendasi dari teman-teman 


\section{Entrepreneurship Bisnis Manajemen Akuntansi (E-BISMA), 2(2), 80-84 \\ R. Yudhistira Adi Seputra, Bhenu Artha}

di lingkaran komunikasi mereka (Sun et al., 2020). Konsumen, dalam hal ini nasabah, akan memilih preferensi berdasarkan keyakinan dan informasi yang didapatkan baik dari bank maupun dari lingkaran komunikasi mereka.

\section{METODE PENELITIAN}

Penelitian ini merupakan penelitian kuantitatif (Bajpai, 2018), yang menggunakan data primer yang didapatkan dari kuesioner yang disampaikan kepada para nasabah Bank BTN Syariah. Sampel yang digunakan dalam penelitian ini sebanyak 110 nasabah. Analisis dalam penelitian ini menggunakan analisis faktor untuk mengetahui faktor-faktor yang menjadi pertimbangan nasabah dalam memilih BTN Syariah dan one way anova, untuk mengetahui perbedaan motivasi nasabah, berdasarkan perbedaan tingkat pendidikan dan pekerjaannya.

Faktor motivasi internal meliputi menjalankan syariat Islam, rela memberi bantuan, dan hak nasabah. Faktor motivasi eksternal terdiri dari papan iklan/spanduk, iklan radio/TV, brosur/selebaran, tawaran petugas, variasi produk, teman, tetangga, lokasi, nama bank, anakanak, anggota keluarga lain, istri/suami, prosedur pelayanan, ketepatan janji, komunikasi karyawan, keramahan karyawan, informasi keuangan pada akhir periode, laporan keuangan transparan, keamanan bertransaksi, kecepatan transaksi, serta keadilan dalam pelayanan.

\section{HASIL DAN PEMBAHASAN}

Faktor-faktor motivasi internal diduga menjadi pertimbangan nasabah dalam menyimpan dananya di BTN Syariah Yogyakarta. Hasil pengujian menunjukkan bahwa 14 variabel saling berhubungan. Hal ini diperlihatkan oleh nilai determinan $|R|$ sebesar 0,015 yang mendekali nol (0), berarti bahwa antar variabel terjadi korelasi. Nilai KMO (KaiserMeyer-Olkin) hasilnya 0,790 yang lebih besar dari 0,5 yang berarti bahwa ada kedekatan antar variabel. Hasil uji Bartlett menunjukkan nilai statistik 437,405 pada taraf signifikansi 0,000 berarti bahwa antar variabel terjadi korelasi (signifikansi $<0,05$ ). Untuk nilai MSA (Measure Sampling of Adequacy) variabel yang termasuk dalam faktor motivasi internal menunjukkan nilai MSA > 0,5, hal ini memperlihatkan ada hubungan antara variabel yang sangat erat.

Pengujian terhadap faktor eksternal menunjukkan bahwa nilai determinan adalah 0,000 , dimana nilai ini mendekati nol (0) maka dapat dinyatakan bahwa antara variabel terjadi korelasi, nilai KMO (Kaiser-Mayer-Olkin) adalah 0,812 dimana nilainya lebih besar dari 0,5 berarti bahwa ada kedekatan antar variabel. Uji Bartlett yang dilaksanakan memperoleh nilai statistik sebesar 846,200 pada taraf signifikansi 0,000, maka dapat disimpulkan bahwa antar variabel terjadi korelasi (signifikansi $<0,05$ ).

Uji anova yang dilaksanakan mendapatkan hasil bahwa tidak terdapat uji yang signifikan dilihat dari tingkat pendidikan dan pekerjaan nasabah. Hal ini berarti motivasi menyimpan dana nasabah adalah relatif sama. Ini mungkin saja terjadi karena faktor internalnya lebih didasari oleh pemahaman syariat agama Islam dan faktor eksternalnya lebih disebabkan karena faktor promosi yang dilakukan oleh pihak BTN Syariah Yogyakarta. Dengan pemahaman syariah Islam yang sama dan obyektif, maka akan memunculkan motivasi internal yang tidak berbeda, sehingga tidak terdapat perbedaan yang 
nyata dalam motivasi internalnya dalam hal penentuan menyimpan dana dan dengan melalui promosi, yang merupakan motivasi eksternal responden penelitian, menunjukkan bahwa orang dengan pekerjaan yang berbeda memiliki motivasi eksternal yang tidak berbeda dalam menyimpan dana di BTN Syariah Yogyakarta.

\section{KESIMPULAN DAN SARAN}

Hasil penelitian menunjukkan bahwa faktor-faktor motivasi internal dan eksternal menjadi pertimbangan nasabah dalam menyimpan dana di BTN Syariah Yogyakarta. Hasil selanjutnya menunjukkan bahwa tidak terdapat perbedaan motivasi internal dan eksternal nasabah dilihat dari tingkat pendidikan dan pekerjaannya. Hal ini disebabkan oleh pemahaman yang relatif sama pada kalangan nasabah BTN Syariah Yogyakarta. Saran untuk penelitian selanjutnya dapat meneliti faktor yang dipengaruhi oleh motivasi misalnya kinerja. Agama dan community service merupakan faktor terpenting yang menentukan potensi penggunaan metode keuangan Islam (Gait \& Worthington, 2015). Kepercayaan pelanggan yang lebih tinggi meningkatkan keakraban pelanggan, komitmen agama yang lebih kuat juga memperkuat keakraban pelanggan, dan telah dipastikan bahwa keintiman nasabah meningkatkan komitmen relasional antar nasabah di bank syariah di Indonesia (Nora, 2019).

\section{DAFTAR PUSTAKA}

Bajpai, N. (2018). Business Research Methods. Pearson India.

Bastari, A., Eliyana, A., Syabarrudin, A., Arief, Z., \& Emur, A. P. (2020). Digitalization in banking sector: the role of intrinsic motivation. Heliyon, 6(12), 1-12.

Chaurasia, S. S., Verma, S., \& Singh, V. (2019). Exploring the intention to use M-payment in India: Role of extrinsic motivation, intrinsic motivation and perceived demonetization regulation. Transforming Government: People, Process and Policy, 13(3-4), 276-305.

Çokgezen, M., \& Kuran, T. (2015). Between consumer demand and Islamic law: The evolution of Islamic credit cards in Turkey. Journal of Comparative Economics, 43(4), 862-882.

Fathonih, A., Anggadwita, G., \& Ibraimi, S. (2019). Sharia venture capital as financing alternative of Muslim entrepreneurs: Opportunities, challenges and future research directions. Journal of Enterprising Communities, 13(3), 333-352.

Gait, A., \& Worthington, A. (2015). Attitudes of Libyan retail consumers toward Islamic methods of finance. International Journal of Islamic and Middle Eastern Finance and Management, 8(4), 439-454.

Hrbackova, K., \& Suchankova, E. (2016). Self-Determination Approach to Understanding of Motivation in Students of Helping Professions. Procedia - Social and Behavioral Sciences, 217, 688-696.

Hsu, L. (2017). EFL Learners' Acceptance of Technology in a Computer-Assisted Language Learning (CALL) Context: The Role of Intrinsic-Extrinsic Motivation in English Learning. International Journal of Information and Education Technology, 7(9), 679685. 
Nora, L. (2019). Trust, commitment, and customer knowledge: Clarifying relational commitments and linking them to repurchasing intentions. Management Decision, 57(11), 3134-3158.

Ryan, R. M., \& Deci, E. L. (2000). Self-Determination Theory and The Facilitation of Intrinsic Motivation, Social Development, and Well-Being. The American Phsycologist, 55, 68-78.

Sun, X., Hou, S., Cai, N., \& Ma, W. (2020). Product information diffusion model and reasoning process in consumer behavior. Heliyon, 6(12), 1-10.

Xu, J., Du, J., Wang, C., Liu, F., Huang, B., Zhang, M., \& Xie, J. (2020). Intrinsic motivation, favorability, time management, and achievement: A cross-lagged panel analysis. Learning and Motivation, 72, 101677.

Zhang, S., Zhao, J., \& Tan, W. (2008). Extending TAM for Online Learning Systems: An Intrinsic Motivation Perspective. Tsinghua Science and Technology, 13(3), 312-317. 